\title{
PRÁTICAS INOVADORAS E ESTILO DE LIDERANÇA NA GESTÃO PÚBLICA MUNICIPAL PARAENSE
}

\section{LEADERSHIP STYLE AND INNOVATIVE PRACTICES IN MUNICIPAL PUBLIC MANAGEMENT}

Milton Cordeiro Farias Filho *

Professor do Mestrado em Administração da Universidade da Amazônia - UNAMA

Professor-Colaborador do Mestrado em Ciência Política e do Mestrado Profissional em Gestão Pública da

Universidade Federal do Pará - UFPA

Coordenador Administrativo da Escola do Legislativo do Estado do Pará

Belém, PA, Brasil

E-mail: mcffarias@gmail.com

Shirle Meira Miranda

Mestre em Administração pela Universidade da Amazônia - UNAMA

Belém, PA, Brasil

E-mail: shirlemeira@hotmail.com

\section{RESUMO}

Este artigo trata da relação entre práticas inovadoras e estilo de liderança na gestão pública municipal. A literatura internacional vem demonstrando essa relação, centrando as análises em variáveis internas (organização, perfil do gestor) e externas (sistema político, desenho institucional). O objetivo da pesquisa foi verificar de que forma o estilo de liderança do gestor influencia a adoção de práticas inovadoras. Foram selecionadas quatro práticas inovadoras adotadas em três municípios de diferentes regiões do estado do Pará. Como procedimento foi feita análise de documentos sobre as práticas inovadoras adotadas, um levantamento do tipo survey com 69 servidores e entrevista com gestores (secretários e prefeitos). Os resultados indicam que as experiências promoveram a integração das áreas e de esferas de governos, indicando a possibilidade de replicação, porém restritas as poucas políticas. O estilo de liderança foi considerado positivo para a adoção das práticas. Conclui que as práticas criativas e inovadoras dependem do estilo da liderança do gestor, do ambiente institucional, da legitimidade da organização e da autoridade conferida ao gestor.

Palavras-chave: Práticas Inovadoras. Liderança. Gestão Pública. Município.

\section{ABSTRACT}

This article deals with the relationship between innovative practice and leadership style in municipal management. The international literature has demonstrated this relationship by focusing the analysis on internal variables (organization manager profile) and external (political system, institutional drawing). The objective of the research was to check how the manager's leadership style influences the adoption of innovative practices. Were selected four innovative practices in three municipalities in different regions of the state of Pará. Data collection procedure were done by means of documents on innovative practices, a survey with 69 servers and interviews with managers (secretaries and mayors). The results indicate that the experiences promoted the integration of the areas and levels of government, indicating the possibility of replication, but restricted to a few policies. The leadership style was considered positive for the adoption of practices. Concludes that the creative and innovative practices depend on the leadership style of the manager, the institutional environment, the legitimacy of the organization and authority vested in the manager.

Keywords: Innovative Practices. Leadership. Public Management. Municipality.

Data de submissão: 17 de fevereiro de 2016.

Data de aprovação: 4 de junho de 2016. 


\section{INTRODUÇÃO}

A produção científica sobre a administração pública brasileira começa a descrever novas práticas de gestão. No entanto, o ambiente da gestão pública ainda convive com práticas tradicionais. Isto se deve, em grande parte, aos aspectos culturais ainda "enraizados" no cotidiano das organizações de gestão estatal, o que deixa a percepção, por parte da sociedade em geral, de que estas organizações são pouco produtivas, ineficientes e dificultam o desenvolvimento socioeconômico nacional.

Inovação e liderança já não são temas muito comuns no estudo de organizações do setor privado, porém os discursos e as práticas, até então dominante do ambiente empresarial, vão sendo incorporadas no cotidiano da gestão estatal. Mesmo assim, os resquícios de disfunções burocráticas ainda prevalecem no cotidiano das organizações estatais, tais como a ausência de competição, estabilidade funcional excessiva e regimentos rígidos interferem de forma negativa no desempenho dos líderes do setor público.

Entretanto, há organizações estatais que mesmo limitadas pelos condicionantes culturais e normativos conseguem empreender mudanças e inovações. Diante desta perspectiva, este artigo relata uma pesquisa movida pelas seguintes questões: a) as práticas inovadoras na gestão de organizações públicas municipais têm relação com o estilo de lideranças de seus gestores? b) qual o estilo de liderança predominante nas organizações públicas municipais que adotaram práticas inovadoras?

Após consulta em bases de textos internacionais (Ebsco, ScienceDirect) e nacionais (Periódicos Capes, Scielo), foram encontradas poucas pesquisas sobre práticas inovadoras na gestão pública municipal. Na região Norte não há registro de pesquisa sobre o tema. O que justifica esta pesquisa, também por ser esta região distante dos centros de referência na formação de profissionais em gestão pública. Além disso, os municípios pesquisados estão localizados em áreas de diferente formação socioeconômica, política e cultural, fator este que pode interferir na forma como gestores exercem liderança e administram as organizações estatais e percebem a função dessas organizações.

O objetivo da pesquisa foi verificar de que forma o estilo de liderança do gestor influencia a adoção de práticas inovadoras na gestão municipal. Para isso a pesquisa se desenvolveu em três etapas: a) seleção dos municípios (três municípios em diferentes regiões do estado) que adotaram práticas consideradas inovadoras, de acordo com os critérios de inovação de Spink (2003) e de práticas inovadoras adotadas por Farah $(2005 ; 2006)$; b) levantamento e análise documental sobre as práticas adotadas e um survey com 69 servidores diretamente envolvidos nas práticas estudadas (quatro práticas inovadoras); c) realização de entrevistas com líderes responsáveis (gestores) pelas práticas inovadoras, observação livre e conversas com outros servidores das organizações que adotaram tais práticas.

O artigo trás além desta introdução, uma seção que trata das práticas inovadoras na administração pública, na literatura nacional e internacional; a segunda seção trata das abordagens de liderança, inclusive no ambiente da gestão pública; a terceira seção expõe o método e os procedimentos de pesquisa; a quarta seção trata dos resultados e discussão, mostrando que o estilo de liderança foi reconhecido como fator fundamental para implantação de práticas inovadoras, além de concluir que a adoção de práticas inovadoras depende de variados fatores externos e internos as organizações. 


\section{REFERENCIAL TEÓRICO}

\section{Administração Pública e Inovação na Gestão}

Experiências internacionais recentes relatadas em alguns trabalhos mostram que a implantação de "reformas" no setor público não é simples, pois vários fatores interferem na adoção de práticas inovadoras que buscam dar mais eficiência na gestão estatal. O estudo de Kim (2010) em unidades subnacionais nos Estados Unidos (esfera estadual) mostra que a implantação de práticas empresariais simples como terceirização e privatização não foram capazes de produzir eficiência e eficácia. Para o autor, a maioria das características organizacionais influencia os gestores, logo estruturas e estratégias organizacionais precisam ser ajustadas para estimular a atividade empresarial e a introdução de uma cultura voltada para gestão orientada por oportunidade.

Da mesma forma Damanpour e Schaneider (2009) estudaram as características dos gestores públicos em 725 governos locais nos Estados Unidos, a partir de 25 experiências, e relacionaram com as características das inovações e da adoção, concluindo que o papel dos gestores foi importante para a adoção das inovações. Para estes autores não basta adotar uma prática inovadora, pois é necessário também compreender se os gestores estão preparados para receber e gerenciar a inovação.

Outra experiência foi a dos chamados "e-governos" na gestão municipal nos Estados Unidos. Nos casos estudados os autores (NELSON; SVARA, 2012) descobriram taxas de inovação mais elevadas onde existiam certas características dos governos aliadas as variáveis externas, como a maior taxa de urbanização, maior população, maior densidade demográfica e menores taxas de desemprego. Na variável maior densidade populacional há divergência com o estudo de Boyne et al (2005) que encontraram nesta variável um efeito negativo para a inovação. Logo, mesmo que variáveis externas sejam importantes, as formas como se conduz o governo (variável interna) são importantes.

$\mathrm{Na}$ mesma direção Jun e Weare (2011) estudaram a relação entre motivação institucional e programas inovadores de "e-governo" na gestão pública também em municípios dos Estados Unidos. Para os autores as motivações externas são mais significativas para que estas inovações sejam implantadas e que esta é uma tendência na gestão municipal daquele país. Os fatores externos também são apontados por Boyne et al (2005) nas experiências de gestão municipal no mesmo país. No entanto, estes autores sustentam que grande parte dos estudos de inovação na gestão não se volta para a inovação em si, e sim para adoção de práticas planejadas em outras esferas, demonstrando ainda que a inovação só é bem-sucedida quando concentrada em um número limitado de serviços e a partir de uma experiência prévia.

Estudo em outras regiões (Catalunha, Espanha), como o de Esteve, Boyne e Sierra (2013) mostram que não foi suficiente ter projetos e programas voltados para tal fim. Foi fundamental nessas experiências o papel desempenhado pelos executivos que estavam na liderança do processo. Além disso, os autores encontraram a variável grau de instrução elevado como fator positivo e idade mais elevada como fator negativo para a adoção de práticas inovadoras.

No Brasil, a partir das reformas administrativas experimentadas, dois modelos organizacionais sugiram: a administração pública gerencial e o governo empreendedor. Esses modelos se fundamentam em princípios e diretrizes que visam à melhora da efetividade da gestão das organizações públicas buscando 
eficiência, eficácia e competitividade (SECCHI, 2009). O desafio era instalar sistemas administrativos que pudessem avançar rumo ao desenvolvimento com uso efetivo de seus recursos (MARCELINO, 2003).

Na percepção de Pires e Macedo (2006) a cultura conservadora, hierarquizada e burocrática, originária dos modelos de gestão tradicional, cujo interesse particular ainda tem destaque, tende a se perpetuar e sua transformação necessita de tempo e de um processo longo de construção social para de fato ocorrer.

Secchi (2009) argumenta que em longo prazo os modelos propostos de reforma possuem potencial para gerar bons resultados, no entanto o autor adverte para os efeitos mínimos gerados pelas "reformas" na administração pública. Na mesma direção, Rezende (2004) defende que a falha sequencial foi um dos principais motivos para que a experiência de modernização da gestão pública na esfera federal no Brasil não tivesse obtido o êxito esperado. No entanto, Bresser Pereira (2003) sustenta outro argumento para esses "fracassos" ao justificá-lo como uma relação entre auto interesse e incompetência gerencial.

$\mathrm{Na}$ gestão pública em geral e, em especial, em governos subnacionais, o tema inovação vem ganhando importância. As razões podem ser atribuídas a vários fatores. Ao realizar estudo no banco de dados de programas e projetos governamentais inscritos em 1996, no "Programa Gestão Pública e Cidadania", Farah (1997) identificou algumas tendências de mudanças nas práticas inovadoras da administração pública em esferas estadual e municipal.

Assim como Farah (1997), Pinho e Santana (1998) também realizaram análises empíricas sobre o programa e construíram categorias que pudessem classificar as intervenções municipais como inovadoras, são elas: a) gestão democrática cujo objetivo é impedir o clientelismo predominante na gestão pública; b) descentralização e desburocratização dos serviços públicos visando romper com o modelo tradicional de administração centralizadora; c) inclusão dos marginalizados e das minorias; $d$ ) resgate de valores tradicionais que se perderam na contemporaneidade; e) criação de novos valores para enfrentar o processo de desenvolvimento atual.

Por sua vez Spink (2003, p.2) considera uma prática como inovadora na gestão pública quando ela representa uma mudança substantiva em relação às anteriores, apresenta a possibilidade de replicação, amplia ou reforça a comunicação com a sociedade, utiliza recursos de forma responsável e estimula práticas autônomas e autossustentadas. Aqui apresentamos uma diferença entre inovação e práticas inovadoras. A inovação como um "monopólio temporário" (ALCHIAN; DEMSETZ, 2007) busca a diferenciação para melhoria da competividade; já a prática inovadora é um exemplo a ser seguido e busca difundir ou replicar a prática para outras organizações.

\section{Sobre Liderança}

A maioria das teorias e conceitos sobre liderança não tem sido testada em ambientes de organizações públicas. Isso pode levar a enganos na aplicação (VILLORIA; IGLESIAS, 2011). Embora existam elementos comuns nas várias definições encontradas na literatura, não há um consenso em torno do conceito. Bryman (2009) sustenta que o uso da terminologia no cotidiano afeta o modo como é definida. Já Bergamini (1994) diz que liderança quase sempre está ligada a um fenômeno grupal que envolve duas ou mais pessoas em processo de influência exercida de maneira intencional pelo líder sobre seus liderados. 
A liderança no setor público é importante para explicar mudança e continuidade e sua compreensão e vai além do quadro conceitual cognitivo, pois envolve o sistema político e seus objetivos do mandato governamental (VILLORIA; IGLESIAS, 2011). Na concepção de Hersey e Blanchard (1986) liderança é sempre definida como o processo de influenciar as atividades de um indivíduo ou grupo para a consecução de um objetivo em uma dada situação e não tem relação com qualquer tipo particular de organização. Já para Bryman (2009), elementos como influência, grupo e metas estão presentes nas diversas definições.

A trajetória do conceito de liderança pode ser dividida em quatro estágios principais, cada um deles associado a um período: a) a abordagem do traço pessoal que predominou até o final dos anos 1940; b) a abordagem do estilo de liderança que se manteve forte até o final dos anos 60; c) a abordagem contingencial que teve seu ápice entre o final dos anos 1960 e início dos 1980; c) a abordagem da nova liderança com maior influência a partir dos anos 1980 (BRYMAN, 2009).

Van Wart (2003) propõe cinco possíveis definições de liderança em contexto administrativo, são elas: a) liderança como processo de fornecer resultados requeridos de forma autorizada, eficiente, eficaz e legal (responsabilidade política); b) processo de desenvolvimento e apoio aos seguidores que fornecem resultados (liderança afetiva); c) processo alinhado à organização com seu ambiente, como as macro alterações necessárias para realinhar a cultura; d) liderança é ter foco nos serviços ou na missão ética; e) composto para proporcionar desempenho técnico, direção interna para seguidores e externa (orientação para o serviço).

A abordagem do estilo de liderança sinalizou para uma mudança no foco que até então vinha sendo estudado. Enquanto a abordagem dos traços de personalidade chamou a atenção para os tipos de pessoas que se tornaram líderes. A abordagem do estilo de liderança centrou a atenção no comportamento dos líderes, afirmando que este poderia ser modificado, dando ênfase no treinamento e não mais na seleção dos líderes (BRYMAN, 2009). Nessa perspectiva há uma rejeição ao fator "natural" para explicação do fenômeno da liderança, passando a considerar a possibilidade de desenvolvimento de líderes por meio de treinamento.

O estilo de liderança tem suas implicações no relacionamento do grupo. Três estilos de liderança, de acordo com Sobral e Peci (2008), têm prevalecido: a) estilo democrático, cuja ênfase está na participação, no envolvimento dos funcionários nas tomadas de decisões, na delegação de autoridade, na preocupação com as relações humanas no trabalho. O poder do líder precisa ser legitimado pelo grupo. b) estilo autocrático, cuja ênfase está na autoridade, na centralização do poder e na execução da tarefa. O poder do líder é delegado e se fortalece pela posição assumida e pela capacidade de cumprimento destas tarefas; c) estilo laissez-faire, com a liderança caracterizada pela ausência de direcionamento, pois o líder deixa o grupo à vontade para agir de acordo com sua conveniência.

Com a evolução dos estudos a abordagem sobre o estilo de liderança que buscava identificar o comportamento ideal do líder começou a demonstrar suas fragilidades e seu caráter pouco realista. As pesquisas começaram a mostrar que fazer um prognóstico sobre o êxito da liderança podia ser tão ou mais complexo do que identificar traços ou comportamentos (MELO, 2001). Surge assim a abordagem contingencial. Para Hersey e Blanchard (1986), o enfoque situacional estuda o comportamento tal como é observado no ambiente, distanciando da compreensão da liderança enquanto uma habilidade hipotética ou potencialidade inata ou adquirida acrescentam ainda que a ênfase no comportamento e no ambiente torna possível, através do treinamento, da adaptação dos estilos de liderança as mais variadas situações. 
A partir dos anos 80 os estudos sobre liderança foram influenciados pela abordagem da nova liderança. A expressão tem sido utilizada, segundo Bryman (2009), para descrever e categorizar uma série de abordagens sobre o tema. São vários os termos utilizados para apresentar os novos tipos de liderança como: liderança transformacional, liderança carismática, liderança visionária ou somente liderança. Nesta concepção, amplia-se o conceito de liderança, que passou a ser compreendida como a capacidade de modificar o comportamento das pessoas pela interação entre o líder e seus seguidores (BASS, 1985).

É fato que as organizações públicas são diferentes das organizações privadas, pois estão submetidas a um campo político difuso, muitas vezes complexo (THOENIG, 2007) e a controles mais jurídicos e políticos do que técnicos e administrativos. Hooijberg e Choi (2001), afirmam que enquanto líderes das organizações públicas estão imersos em uma infinidade de objetivos, com diferentes racionalidades e interesses políticos diversos; os líderes das organizações privadas trabalham com objetivos mais transparentes, voltados para os resultados em forma de lucro, com maior facilidade de mensuração. Já para Villoria e Iglesias (2011) a necessidade de legitimação e o nível de institucionalização da organização, onde o líder atua, são fatores importantes a considerar para uma visão mais precisa da liderança, dada a variação de posições e diferenças entre as organizações públicas.

Van Slyk e Alexandre (2006) defendem que a pouca flexibilidade na gestão estatal impõe limites para seus resultados. Já para Osborne e Gaebler (1998) a gestão estatal, por ser conduzida por excesso de regimentos, normas e leis, apresenta pouco espaço à criatividade e inovação. Por outro lado, a teoria das disfunções burocrática (MERTON, 1970) dá explicações suficientes para compreender que as dificuldades e os limites da administração pública, especialmente a nacional, não são gerados pela burocracia, da forma como teorizada por Weber (1974), e sim por suas disfunções ou desajuste entre estrutura social e as relações sociais.

De outro lado Bresser Pereira (2003) e Rezende (2004), embora partindo de pontos diferentes e até divergentes, evidenciam um mesmo aspecto central para a compreensão dos problemas da gestão estatal: auto interesse aliado à incompetência técnica, reformas mal conduzidas e ineficiência gerada pela rigidez dos procedimentos. Aliado a estes fatores estão o ambiente político não propício e a cultura organizacional desfavorável (PIRES; MACEDO, 2006), o que explica a tese de Osborne e Gaebler (1998) de que um ambiente pouco propício à inovação e com dificuldades para o exercício da liderança geralmente é marcado por excesso de formalização e impedimento à criatividade.

Resultado de uma pesquisa realizada pelo Ministério do Planejamento, Orçamento e Gestão - MPOG, em 2002 (BRASIL, 2002), sobre a temática da liderança no setor público a partir das experiências práticas de países membros da Organização de Cooperação e Desenvolvimento Econômico - OCDE, revelou que muitos países têm conferido alta prioridade ao assunto ao longo dos últimos anos, especialmente por quatro motivos: a) um ambiente que requer um novo estilo de liderança, com pessoas que pensem e ajam de modo global $\mathrm{e}$ local; b) liderança com percepção sobre o comando e o controle, com papeis bem distintos entre líderes e liderados; c) liderança mais voltada aos atributos relacionados à integridade, visão, capacidade de discernimento e de inspirar os outros e coragem para inovar; d) uma nova liderança que envolve todos os níveis da organização, diferente dos modelos tradicionais em que os líderes eram tratados como pessoas raras que estavam em posições superiores. 
Como base de análise dos estilos de liderança dos gestores pesquisados a pesquisa teve como parâmetro conceitual para análise empírica quatro tipos de liderança: a) estilo transformacional (BRYMAN, 2009); b) estilo situacional (HERSEY; BLANCHARD, 1986); c) estilo autoritário ou autocrático (SOBRAL; PECl, 2008); estilo democrático (SOBRAL; PECI, 2008).

\section{MÉTODO E PROCEDIMENTO}

O desenvolvimento da pesquisa se deu em três etapas. A primeira inicia com a definição dos critérios de seleção dos municípios do estado objeto da pesquisa, o estado do Pará, sendo: a) identificação de gestores com dois mandatos consecutivos, pela facilidade de verificar as práticas e sua continuidade; b) buscar municípios localizados em diferentes regiões do estado, pois isso evitaria as "semelhanças sociopolíticas e culturais" que a proximidade geográfica possibilita.

Os critérios de práticas inovadoras foram os utilizados por Spink (2003) e Farah (2005). Com base nestes critérios, foram selecionados 12 municípios com tais práticas, porém, apenas três aceitaram participar da pesquisa e também tinham registros sobre as práticas. São eles: Castanhal (Nordeste-PA), Paragominas (Sudeste-PA) e Óbidos (Oeste-PA). Assim, os projetos estudados foram: "Gestão Eficiente da Merenda Escolar" e "Gestão Ambiental no Município Verde", em Paragominas-PA; "Gestão Eficiente da Merenda Escolar", em Castanhal-PA; e "Escola de Tempo Integral", em Óbidos-PA.

$\mathrm{Na}$ segunda etapa, os procedimentos de coleta de dados e informações foram: a) consulta a documentos, como projetos, relatórios e imagens sobre as práticas inovadoras, além de visitas aos locais de implantação das práticas selecionadas e conversas informais com servidores que atuavam diretamente nos projetos (oito servidores); b) realização de um survey com uso de um questionário fechado com escala de cinco pontos: (1) Discordo totalmente; (2) Discordo; (3) Nem Concordo, Nem Discordo; (4) Concordo; (5) Concordo Totalmente. Os participantes do survey foram os 69 servidores diretamente envolvidos com as práticas inovadoras nos três municípios (coordenadores, servidores efetivos e temporários que atuaram no período estudado)

$\mathrm{Na}$ terceira etapa, foram realizadas entrevistas estruturadas com gestores dos três municípios (prefeito de cada município), obedecendo as seguintes dimensões: a) estratégias utilizadas pelo líder para motivar sua equipe; b) formas de tomada de decisões; c) nível de consideração e confiança nos liderados visando elevar o potencial de desempenho da equipe; d) nível de estímulo intelectual para autonomia dos liderados diante de desafios e problemas. As referências para o planejamento do survey e das entrevistas foram Farias Filho e Arruda Filho (2013). 


\section{RESULTADOS E DISCUSSÃO}

\section{A Gestão Eficiente da Merenda Escolar nos Município de Paragominas e Castanhal}

O governo Federal tem incentivado os governos subnacionais a gerir de forma eficiente a merenda escolar em seus municípios. Para isso criou o Programa Nacional de Alimentação Escolar - PNAE, cujo objetivo é atender às necessidades nutricionais de crianças e adolescentes durante sua permanência na escola, cooperando para melhoria do rendimento escolar dos alunos, assim como para a aquisição de hábitos alimentares mais saudáveis.

Incentivado por este programa e pelo concurso realizado em nível nacional pela ONG "Ação Fome Zero", diversos municípios passaram a rever suas práticas relacionadas à qualidade da merenda oferecida nas escolas. A ONG busca contribuir para o desenvolvimento social sustentável e lançou em 2004 o Prêmio "Gestor Eficiente da Merenda Escolar". Desde então, as secretarias de educação dos municípios de Paragominas e Castanhal passaram a desenvolver práticas voltadas para a qualidade na alimentação escolar, conscientização de estudantes e familiares quanto à importância da alimentação saudável, participação da sociedade (agricultores e familiares) no processo de execução e gestão do Programa da merenda escolar.

Outras características do Programa foram a inclusão de escolas de comunidades quilombolas e indígenas, a parceria firmada entre diversos órgãos públicos como Serviço Brasileiro de Apoio as Micro e Pequenas Empresas - SEBRAE e Empresa de Assistência Técnica e Extensão Rural EMATER, trabalho desenvolvido de forma intersetorial com as secretarias municipais de agricultura e de meio ambiente dos municípios. Atualmente os municípios se destacam com frequentes premiações nesta categoria em nível nacional.

[...] Até o inicio do ano de 2004 a base da alimentação eram formulados (produtos industrializados/semiprontos), após junho de 2004 atingimos a meta do FNE que é introdução de $70 \%$ dos produtos básicos como arroz, feijão, macarrão entre outros na merenda escolar [...]. (PREFEITURA..., [20--])

[...] Houve a introdução da agricultura familiar, os agricultores locais também foram evoluindo [...] se organizaram em associações e cooperativas e se documentaram com suas aptidões oficiais [...]. (PREFEITURA..., [20--])

Nesta perspectiva de melhoria da qualidade de vida de forma sustentável, a estrutura física das escolas também vem sofrendo modificações para adequarem as normas de higiene e manipulação dos alimentos, conforme estabelece o Fundo Nacional de Desenvolvimento Escolar - FNDE e da Agência Nacional de Vigilância Sanitária - ANVISA.

[...] Muitas escolas passaram por reformas visando oferecer um ambiente adequado para o aprendizado do aluno. A preocupação não é somente com a merenda de qualidade, mas com um ambiente escolar saudável e estimulante. Toda a equipe da escola desde o porteiro a Diretora tem a responsabilidade de conservar este ambiente e fazer o melhor pela escola. [...]. (Entrevista, Diretora de Escola, Ago./2013). 
Os resultados do Programa de melhoria da gestão da merenda escolar permitiram classificá-lo como uma prática inovadora à medida que as secretarias de educação criaram alternativas para enfrentarem os desafios propostos pelo Prêmio "Gestor Eficiente da Merenda Escolar", não se limitando somente a mudança de cardápio nas escolas.

As secretarias de educação incentivaram novas concepções de alimentação de crianças, jovens, adultos, pais, professores e da comunidade em geral, modificando os hábitos alimentares, promovendo a melhoria na saúde dos estudantes, além da inclusão de muitas famílias nos programas e da integração das áreas de saúde, educação e agricultura.

As duas práticas revelam que os gestores que conduziram o processo estavam preparados, como apontam Damanpour e Schaneider (2009), já que mesmo inovando na prática, conseguiram dar continuidade. Além disso, as práticas promoveram a inclusão de segmentos, antes não atendidos pelas ações de governos anteriores, como comunidades quilombolas e indígenas, fez integração entre esferas de governo (federal: SEBRAE, estadual: EMATER com a sociedade: ONG), na mesma forma como identificou Farah (1997) e propôs Spink (2003) ao mencionar que práticas inovadoras devem proporcionar a possibilidade de replicação.

As duas experiências demonstraram que fatores externos, como defendem Jun e Weare (2011), influenciaram a adoção das práticas, já o prêmio promovido pela ONG reflete tal influência. Essas experiências também mostram que práticas planejadas em outras esferas de governo e sua adoção em um número limitado de serviços aumentam a probabilidade de êxito, como concluíram Boyne et al (2005) nas experiências relatadas de governos locais nos EUA.

\section{Educação Ambiental e o "Município Verde": Município de Paragominas}

O município de Paragominas adotou o Projeto "Município Verde", lançado pelo governo federal para os municípios da Amazônia, entre os anos de 2007 e 2008, cujo objetivo era fomentar a geração de riqueza sem desmatamento, utilizando os recursos disponíveis de forma criativa, garantindo assim o desenvolvimento local sustentável. Para alcançar os objetivos propostos o gestor municipal contou com o apoio de diversas organizações locais e da sociedade civil para aderir ao pacto pelo desmatamento zero.

Diante da necessidade de ampliar e aprofundar o debate sobre meio ambiente e desenvolvimento sustentável no cotidiano da sala de aula, em 2007, foram firmadas parcerias com a Mineradora Vale e a Comunidade Educativa CEDAC para a formação de professores, com base no que é assegurado pela Política Nacional de Educação Ambiental (Lei №. 9795/99). No ano de 2008 inicia então a formação continuada em educação ambiental no seguimento de $6^{\circ}$ ao $9^{\circ}$ ano.

(...) Uma formação ambiental deve ter como objetivo ir além do ensino de conhecimentos sobre questões ambientais tanto no que se refere aos professores quanto aos alunos. Para que seja efetiva, precisa buscar promover transformações no modo de pensar o mundo, no modo de se inserir nele, de avaliar as próprias atitudes, bem como despertar o agir de modo sustentável (...). (PREFEITURA..., 2009)

A educação ambiental nesta nova perspectiva se configura como um dos eixos estratégicos do Projeto "Município Verde" e tem como objetivo romper com os modelos tradicionais de ensino que reduzem a educação ambiental a atividades eventuais dentro da escola. O Projeto visa estimular progressivamente a 
incorporação de valores e atitudes que alcance os familiares e a sociedade local. A partir desse projeto, outros complementares foram sendo desenvolvidos, como um parque público temático no centro da cidade.

Esta prática também encontra consonância com as práticas identificadas por Farah (1997) por envolver vários atores (empresas, Ongs e outros), ampliar a participação da sociedade, permitir um melhor controle e avaliação da prática. Ela segue também as orientações de Spink (2003), além de se enquadrar nas categorias construídas por Pinho e Santana (1998), no que se refere à inclusão dos marginalizados e das minorias, criação de novos valores e descentralização dos serviços.

Da mesma forma que as outras experiências de gestão da merenda escolar, que são influenciadas por agentes externos e induzidas por outras esferas de governo, neste caso a esfera federal. Portanto, confirmam o que Boyne et al (2005) e Jun e Weare (2011) encontraram em suas pesquisas, o que pode demonstrar que práticas inovadoras em governos locais tem como fator fundamental as influências e pressões externas.

\section{A Escola de Tempo Integral - ETI no Município de Óbidos}

A Secretária de Educação do Município de Óbidos, no ano de 2010, implantou como experiência na cidade a escola de tempo integral em uma de suas unidades, como na Escola Municipal de Educação Infantil e Ensino Fundamental "Frei Edmundo Bonckosch", como uma experiência piloto. O projeto é destinado a atender crianças e adolescentes de baixo poder aquisitivo, buscando melhoria na qualidade de ensino.

A escola fica localizada na periferia da cidade, seus alunos são oriundos de família de baixa renda, cujos pais são trabalhadores da indústria de castanha, frigorífico, domésticas, vendedores ambulantes, além das famílias que trabalham em pequenas lavouras e carvoarias o dia inteiro. Realidade esta que obrigam estes pais a deixarem seus filhos sozinhos em casa.

[...] A proposta da criação da ETI revelou-se como uma alternativa viável para mudar a realidade de crianças e adolescentes da periferia da cidade. Seu processo de implantação foi amplamente debatido junto à comunidade, professores, técnicos e todo o quadro de funcionários da escola. Assim, a proposta teve uma aceitação positiva tanto por parte de funcionários como pela comunidade local por entender os benefícios que esta traria [...]. (Entrevista, Gestor C, Out./2013)

[...] Quebrar velhas tradições, mudar paradigmas e trabalhar com poucos recursos são os grandes desafios para um gestor quando se quer implantar algo novo na gestão pública. Fazer as pessoas compreenderem a importância e a necessidade do projeto foi algo complicado mas não foi suficiente para desistirmos da ideia [...]. (Entrevista, Gestor C, Out./2013)

Esta prática foi considerada inovadora não pelo seu ineditismo, já que a Escola de Tempo Integral é encontrada em diversas cidades do país, e sim porque mudou práticas anteriores, ampliando o acesso de crianças e adolescentes a um processo educacional integral, buscando a melhoria biopsicossocial dos estudantes.

Essas práticas mesmo sendo inclusivas, como sugerem Farah (1997), Pinho e Santana (1998) e Spink (2003), representam tentativas dos gestores municipais de atuar em um número reduzido de serviços, na forma como defendem Boyne et al (2005). São experiências que refletem motivações internas e influências e pressões externas, da forma como sugerida por Boyne et al (2005) e Jun e Weare (2011). Os resultados 
também são semelhantes as conclusões de Esteve, Boyne e Sierra (2013) no que se refere ao papel desempenhado pelos gestores.

\section{Estilo de Liderança e sua Relação com Práticas Inovadoras}

Os resultados quanto ao estilo de liderança dos gestores foram próximos nos municípios de Paragominas e Óbidos, pois apresentaram maior consenso nos resultados (soma da frequência para as firmativas "concordo" e "concordo totalmente" ou para as afirmativas "discordo" e "discorso totalmente"). Neste caso o estilo de liderança trnaformacional prevalesceu, seguido bem próximo pelo estilo situacional (Quadro 1).

Os estilos democrático e autoritário apresentaram pouco consenso nas frequencias das respostas para o município de Castanhal. As respostas somadas para o estilo autoritário na forma "concordo" e "concordo totalmente" $(49,7 \%)$ foram semelhantes a soma das respostas "discordo" e "discordo totalmente" $(49,7 \%)$, o que demonstra ausência de um consesnso para a um estilo predominante no município de Castanhal.

Ao contrário dos municípios de Paragominas e Óbidos em que houve um consenso em torno do estilo democrático. Mesmo considerando que em Castanhal este estilo tenha recebido elevada soma percentual $(98,4 \%)$ de respostas "concordo" e "concordo totalmente" para o estilo de lideranaça democrático dos líderes (Quadro 1).

Quadro 1 - Estilos de liderança encontrados nos municípios pesquisados

\begin{tabular}{|c|c|c|c|c|c|c|c|c|c|c|}
\hline \multirow{2}{*}{ Município } & \multicolumn{5}{|c|}{ Autoritário } & \multicolumn{5}{|c|}{ Situacional } \\
\hline & (1) & $(2)$ & $(3)$ & (4) & $(5)$ & $(1)$ & $(2)$ & $(3)$ & (4) & (5) \\
\hline Castanhal (Nordeste-PA) & 26,6 & 15,3 & 7,4 & 35,1 & 14,6 & 0,0 & 0,2 & 17,6 & 50,6 & 31,6 \\
\hline Paragominas (Sudeste-PA) & 4,3 & 12,5 & 11,5 & 34,7 & 37,0 & 0,0 & 3,0 & 16,8 & 47,9 & 32,3 \\
\hline Óbidos (Oeste-PA) & 0,3 & 13,7 & 6,1 & 59,7 & 20,3 & 0,0 & 0,0 & 11,6 & 60,4 & 28,1 \\
\hline \multirow{2}{*}{ Município } & \multicolumn{5}{|c|}{ Democrático } & \multicolumn{5}{|c|}{ Transformacional } \\
\hline & (1) & $(2)$ & (3) & (4) & (5) & (1) & (2) & (3) & (4) & (5) \\
\hline Castanhal (Nordeste-PA) & 0,0 & 0,0 & 1,6 & 65,1 & 33,3 & 0,0 & 0,0 & 2,0 & 33,7 & 64,4 \\
\hline Paragominas (Sudeste-PA) & 0,0 & 0,2 & 6,1 & 45,4 & 48,4 & 0,0 & 0,2 & 9,5 & 48,0 & 42,3 \\
\hline Óbidos (Oeste-PA) & 0,0 & 0,7 & 4,1 & 61,2 & 34,0 & 0,0 & 0,7 & 6,1 & 53,5 & 39,8 \\
\hline
\end{tabular}

Fonte: Pesquisa de campo, 2013.

Já quanto as entrevistas estruturadas, suas respostas mostram que a prática inovadora implantada na Secretaria de Educação de Castanhal está relacionada com as atitudes do seu líder e que seu estilo de liderança foi decisivo para o êxito da prática e que sem a participação do líder a prática inovadora não existiria. Um dos gestores do município se manifesta sobre essa relação:

[...] O líder é o grande responsável para motivar a equipe a se envolver com as ações da prefeitura. Você como líder tem que mostrar o que tem para fazer e colocar na prática o que é fundamental, as inovações precisam acontecer, mas esta atitude parte das determinações do gestor, se este não tiver determinação não acontece nada, ele precisa planejar e cobrar resultados das pessoas. Precisa verificar pessoalmente como as coisas estão acontecendo. Muitas vezes fiz visitas surpresas nas escolas, tomei café com as crianças para verificar de perto a qualidade da merenda. (Entrevista, Gestor A, Set./2013). 
Nos três municípios as lideranças apresentaram padrões de comportamento compatíveis com os diversos estilos, com sutil predominância de um ou outro em cada conjunto de questões. Na concepção de um dos gestores do Município de Óbidos, o novo líder da nova gestão pública tem que ter primordialmente compromisso com as pessoas, com a verdade e seriedade no trato com a coisa pública.

(...) Me considero um líder do novo tempo, das novas demandas da sociedade e da nova gestão pública (...). Liderar é acima de tudo o compromisso com as pessoas, com a verdade e com a seriedade no trato com a coisa pública, o gestor só irar ter o respeito e a consideração das pessoas se tiver este compromisso. Neste contexto me considero um líder atual. Minha equipe sentia segurança na condução dos trabalhos, pois sabia que eu estava por trás e ia assumir as decisões junto com eles. (Entrevista, Gestor C, Out./2013).

Atitudes autoritárias, individualistas e pautadas em regras, normas pré-estabelecidas e fiscalizações demonstraram não ter sido o caminho escolhido pelas lideranças dos municípios pesquisados para liderar suas equipes. As atitudes autoritárias não foram predominantes. Atitudes democráticas e com base no modelo de liderança mais transformacional e situacional prevaleceram na gestão.

O líder precisa ser propositivo, mas dentro de uma equipe. O tempo em que o líder era dono da verdade acabou. O líder precisa passar confiança e vontade de fazer as coisas acontecerem. Não se consegue governar hoje no sistema antigo, como rei, o tempo do dono da verdade acabou, é preciso considerar as equipes de trabalho, suas opiniões, mas principalmente passar confiança para as pessoas. (Entrevista, Gestor C, Out./2013).

O líder tanto pode ajudar como atrapalhar. Ajuda quando é provocador, impõe desafios aos seus liderados, estimula a caminhada para novos horizontes, e dá apoio, acompanha, avalia, planeja junto, aceita as ideias, as limitações dos outros sem desistir deles e reconhece suas próprias limitações. Atrapalha quando acha que sabe tudo e quer fazer tudo sozinho(...). (Entrevista, Gestor C1, Out./2013).

Os resultados para a relação entre estilo de liderança e práticas inovadoras mostram que houve um consenso positivo (Tabela 1). Nos três municípios a soma da frequência das respostas "concordo" e "concordo totalmente" apresentaram resultados semelhantes. Tanto em Castanhal $(89,5 \%)$, como Óbidos $(85,1 \%)$ e Paragominas $(84,5 \%)$ foram feitas indicações de que as práticas inovadoras adotadas estavam diretamente relacionadas com o estilo de liderança do gestor.

Tabela 1 - Relação entre estilo de liderança e práticas inovadoras

\begin{tabular}{lccccc}
\hline \multirow{2}{*}{ Município } & \multicolumn{5}{c}{ Estilo de Liderança - Práticas Inovadoras } \\
\cline { 2 - 6 } & $\mathbf{( 1 )}$ & $\mathbf{( 2 )}$ & $\mathbf{( 3 )}$ & $\mathbf{( 4 )}$ & $\mathbf{( 5 )}$ \\
\hline Castanhal (Nordeste-PA) & 0,7 & 5,0 & 4,8 & 23,5 & 66,0 \\
Paragominas (Sudeste-PA) & 0,2 & 3,0 & 12,3 & 45,4 & 39,1 \\
Óbidos (Oeste-PA) & 0,4 & 4,9 & 9,5 & 33,9 & 51,2 \\
\hline
\end{tabular}

Fonte: Pesquisa de campo, 2013. 
Os resultados demonstram que há um movimento de mudança na gestão das políticas públicas municipais, conforme já percebido por Pinho (2004) e Farah (1997; 2006), mesmo que ainda incipiente e localizado como demonstram Boyne et al (2005) em sua pesquisa. Também revelam que o papel da liderança, a partir das práticas estudadas, está parcialmente relacionado com as proposições de Van Wart (2003), no que se refere às definições de liderança no contexto administrativo.

As práticas identificadas nos três municípios revelam que governos subnacionais buscaram uma gestão mais eficiente do ponto de vista de seus resultados, por meio de iniciativas criativas, duradouras, passiveis de replicação e que alteraram a realidade e a vida das pessoas, como concebida por Spink (2003). Para este autor é essencial que uma prática inovadora seja capaz de produzir mudanças substantivas em relação às práticas anteriores, além de apontar os caminhos para que esta possa ser repetida em outras realidades.

Os resultados revelam também que as práticas estão localizadas em áreas com mais facilidade de serem implantadas (como a educação), mas com grande potencial de serem seguidas por outras localidades. Exceto no caso de Paragominas, cuja prática se transformou em um modelo de desenvolvimento para o município e adotado pelo governo do estado nos anos subsequentes, inclusive ganhando status de Programa de Estado. Esse fato mostra que a prática teve êxito.

Tais resultados confirmam o que foi sugerido por Pinho e Santana (1998), que ao construir categorias para classificar as intervenções municipais como inovadoras apontaram, entre outras, a inclusão dos marginalizados e das minorias, o resgate de valores tradicionais que se perderam na contemporaneidade e a criação de novos valores para enfrentar o processo de desenvolvimento atual como prática inovadora.

Com base nas pesquisas de Farah (1997), no qual se identificou algumas tendências de mudanças na administração pública subnacional referentes a práticas inovadoras, a realidade dos municípios paraenses pesquisados parece seguir a mesma tendência nacional. Ito provavelmente ocorre dada a estruturação dos projetos federais que de algum modo já apontam o caminho a ser seguido, cabendo aos gestores ter habilidade e disposição para fazer adequação destes projetos as suas realidades, de forma criativa e inovadora, mas sob uma liderança não autoritária.

Por outro lado, os resultados revelam que mesmo sem um estilo de liderança predominante, as práticas mostraram que o papel dos líderes foi essencial. Villoria e Iglesias (2011) dão ênfase ao sistema político, objetivos do mandato governamental, necessidade de legitimação e ao nível de institucionalização da organização em que o líder atua. Portanto, fatores externos (BOYNE et al, 2005) interferem significativamente na conduta dos líderes quanto a iniciativa de práticas inovadoras, o que de certa forma passa a modificar o perfil dos gestores municipais como mostram os resultados apontados no relatório do MPOG (BRASIL, 2002).

Apesar dos excessos de regimentos, normas e leis apontados por Osborne e Gaebler (1998), o que reflete a realidade nacional, que deixa a administração pública orientada mais pelos princípios jurídicos e menos pelas ciências gerenciais, além de outros fatores internos apontados por Kim (2010) como desafios a criatividade e a inovação, por parte das lideranças públicas. No caso dos municípios pesquisados, há uma tentativa de buscar formas de gestão mais eficientes e criativas, a partir de práticas inovadoras. 


\section{CONCLUSÃO}

A introdução de práticas criativas e inovadoras no âmbito da gestão pública depende do estilo de cada liderança, mas também do ambiente institucional, da legitimidade da organização e da autoridade do gestor. Fatores internos e externos contam. Para além das mudanças nos processos de gestão e na estrutura organizacional, a inovação na gestão pública municipal é resultado de um processo coletivo que envolve crenças, valores, conhecimento, habilidades e atitudes dos servidores e das lideranças públicas.

Assim, nem sempre a iniciativa de inovar se efetiva, dado que as organizações tendem a repetir processos e padrões arraigados e a adotar comportamentos conservadores, especialmente os princípios jurídicos que condicionam e limitam a criatividade, dão pouca liberdade para as ações guiadas pelos princípios administrativos contemporâneos.

As práticas inovadoras na gestão pública dos municípios estudados mostraram como o estilo de liderança dos gestores e suas posturas influenciaram sua adoção, fato este reconhecido pelos servidores diretamente envolvidos e se manifestaram como fator fundamental para enfrentar as dificuldades inerentes às organizações estudadas.

Para conduzir o aperfeiçoamento da capacidade de gestão e melhorar o desempenho organizacional, cabe ao líder o papel de criar um clima organizacional propício à inovação, e capaz de mobilizar pessoas por meio de um ambiente organizacional motivador. No entanto, a pesquisa não revelou um estilo de liderança predominante, porém os estilos de liderança transformacional e situacional foram mais frequentes nos municípios pesquisados.

A predominância de líderes com perfis mais transformacionais e situacionais demonstrou que o processo de liderança na gestão pública está mudando. Por isso, o estilo de liderança autoritária, que em geral é propagado pelo senso comum como o mais encontrado em organizações públicas, não predominou. Os antigos "chefes" parecem perder espaço nas organizações públicas quando se trata de inovação na gestão.

Mesmo havendo um reconhecimento da importância da liderança nos processos de mudanças na gestão pública, importa aprofundar mais os estudos sobre que tipo de liderança, considerando o contexto da administração pública brasileira, é necessário para implantar inovações em outras esferas de governo. Outras questões podem ser trabalhadas em outras pesquisas como o papel das normas rígidas da legislação como o principal impedimento à criatividade e inovação na gestão pública ou ainda sobre o fator autonomia nos processos de inovação. 


\section{REFERÊNCIAS}

ALCHIAN, A. A.; DEMSETZ, H. Produção, custos de informação e organização econômica. In: Teoria das organizações. (Série RAE-Clássicos). São Paulo: Atlas, 2007.

BASS, B.; RIGGIO, R. E. Transformational leadership. 2ªed. Mahwah, NJ: Lawrence Erlbaum Associates, 2005.

BERGAMINI, C. W. Liderança: administração do sentido. São Paulo: Atlas, 1994.

BOYNE, G. A.; GOULD-WILLIAMS, J. S.; LAW, J.; WLAKER, R. M. Explaining the adoption of innovation: an empirical analysis of public management reform. Government and Policy, v.23, n.3, p.419-435, 2005.

BRASIL. Ministério do Planejamento Orçamento e Gestão. Liderança e setor público no século 21: governança. Brasília, 2002.

BRESSER-PEREIRA, L.C. Incompetência e auto-interesse. Revista Brasileira de Economia, v.57, n.1, p.209-222, 2003.

BRYMAN, A. Liderança nas organizações. In: CLEGG, S. R.; HARDY, C.; NORD, W. R. (Org.). Handbook de estudos organizacionais: ação e análise organizacionais. São Paulo: Atlas, 2009. p.253-277.

DAMANPOUR, F.; SCHNEIDER, M. Characteristics of innovation and innovation adoption in public organizations: assessing the role of managers. Journal of Public Administration Research and Theory, v.19, n.3, p.495-522, 2009.

ESTEVE, M.; BOYNE, G.; SIERRA, V.; YSA, T. Organizational collaboration in the public sector: do chief executives make a difference? Journal of Public Administration Research and Theory, v.23, n.4, p.927-952, 2013.

FARAH, M. F. Gestão pública e cidadania: iniciativas inovadoras na administração subnacional no Brasil. RAP, v.31, n.4, p.126-56, 1997.

FARAH, Marta F. Inovação Pública. Revista GV- Executivo, v.4, n.2, p.41-45, 2005.

FARAH, M. F. Inovação e governo local no Brasil contemporâneo. In: JACOBI, P.; PINHO, J. A. (Org.). Inovação no campo da gestão pública local: novos desafios, novos patamares. Rio de Janeiro: FGV, 2006. p.41-77.

FARIAS FILHO, M. C.; ARRUDA FILHO, E. J. M. Planejamento da pesquisa científica. São Paulo: Atlas, 2014.

HERSEY, P.; BLANCHARD, K. H. Psicologia para administradores: a teoria e as técnicas da liderança situacional. São Paulo: E.P.U., 1986. (obra original em inglês 1970).

HOOIJBERG, R.; CHOI, J. The impact of organizational characteristics on leadership effectiveness models: An examination of leadership in a private and a public sector organization. Administration \& Society, v.33, p.403-431, 2001.

JUN, K.; WEARE, C. Institutional Motivations in the Adoption of Innovations: the case of e-government. Journal of Public Administration Research and Theory, v.21, n.3, p.495-519, 2011.

$\mathrm{KIM}, \mathrm{Y}$. Stimulating entrepreneurial practices in the public sector: the roles of organizational characteristics. Administration \& Society, v.42, n.7, p.780-814, 2010.

MARCELINO, G. F. Em busca da flexibilidade do Estado: o desafio das reformas planejadas no Brasil. RAP, v.37, n.3, 641-59, 2003.

MELO, M. A. Crise federativa, guerra fiscal e "hobbesianismo municipal": efeitos perversos da descentralização? São Paulo em Perspectiva, v.10, n.3, p.11-20, 1996.

MERTON, R. K. Sociologia: teoria e estrutura. São Paulo: Mestre Jou, 1970. (obra original em inglês 1949).

NELSON, K. L.; SVARA, J. H. Form of government still matters: fostering innovation in U.S. municipal governments. The American Review of Public, v.42, n.3, 257-281, 2012.

OSBORNE, D.; GAELBER, T. Reinventando o governo: como o espírito empreendedor está transformando o setor público. $10^{\mathrm{a}}$ ed. Brasília: MH Comunicação, 1998.

PREFEITURA MUNICIPAL DE ÓBIDOS-PA. Relatório de gestão. Óbidos: Documento não publicado, 2009.

PREFEITURA MUNICIPAL DE PARAGOMINAS. Relatório de gestão. Paragominas: Documento não publicado, $200 ?$.

PINHO, J. A. G.; SANTANA, M. W. Inovação na gestão pública no Brasil: uma aproximação teórica conceitual. Trabalho apresentado no XXII Enanpad, Foz do Iguaçu, Setembro de 1998.

PINHO, J A. G. de. Inovação na gestão municipal no Brasil: a voz dos gestores municipais. Cadernos Gestão Pública e Cidadania, v.9, p.9-32, 2004.

PIRES, J. C. de S.; MACEDO, K. B. Cultura organizacional em organizações públicas no Brasil. RAP, v.40, n.1, p.81105,2006 
REZENDE, F. da C. Por que falham as reformas administrativas? Rio de Janeiro: FGV, 2004.

SECCHI, L. Modelos organizacionais e reformas da administração pública. RAP, v.43, n.2, p.347-69, 2009.

SOBRAL, F.; PECl, A. Administração: teoria e prática no contexto brasileiro. São Paulo: Prentice Hall, 2008.

SPINK, P.K. Inovação na perspectiva dos inovadores: a experiência do Programa Gestão Pública e Cidadania.

Cadernos Ebape.Br, v.1, n.2, p.1-13, 2003

THOENIG, J. C. Recuperando a ênfase na dimensão pública dos estudos organizacionais. RAP, (Edição Especial), p.936, 2007.

VAN SLYK, D. M.; ALEXANDRE, R. W. Public service leadership: opportunities for clarity and coherence. The American Review of Public Administration, v.36, p.362-74, 2006.

VAN WART, M.. Public sector leadership theory: an assessment. Public Administration Review, v.63, n.2, p.214-228, 2003.

VILLORIA, M.; IGLESIAS, Á. Leadership in public management: Some theoretical and methodological considerations. Innovar, v.21, n.4, 175-189, 2011.

WEBER, M. Ensaios de sociologia. $3^{a}$ ed., Rio de Janeiro: Zahar, 1974. 